\title{
O EFEITO DO CONSUMO CRÔNICO DE ETANOL NA ABSORÇÃO DUODENAL DE FERRO EM CAMUNDONGOS
}

\author{
Kelly Renata SABINO'1, Andy PETROIANU², Luiz Ronaldo ALBERTI ${ }^{1}$ and \\ Adriana Nunes MACHADO ${ }^{3}$
}

\begin{abstract}
RESUMO - Contexto - Os indivíduos alcoolistas apresentam aumento da concentração hepática de ferro e os mecanismos responsáveis por essa deposição são ainda desconhecidos. Apesar da extensa literatura existente sobre a absorção de ferro nos diferentes estados patológicos, os efeitos do consumo prolongado do etanol não estão totalmente esclarecidos. Objetivos - Determinar a absorção de ferro no duodeno de camundongos após consumo prolongado de etanol, com relação ao controle de camundongos normais. Métodos - Foram utilizados 10 camundongos machos da raça Swiss, distribuídos em dois grupos: grupo $1(\mathrm{n}=5)$ - controle e grupo $2(\mathrm{n}=5)$ - consumo de água com etanol, como única fonte de água ofertada. Os animais foram acompanhados durante 120 dias. Decorrido esse período, isolou-se o duodeno e pela parte oral de cada alça, infundiu-se solução salina contendo ascorbato de ferro II na concentração de $0,016 \mathrm{mg}$ de ferro elemento. O efluente foi coletado nos tempos 20, 40, 60, 80, 100 e 120 minutos. Os resultados foram analisados pelo teste Mann-Whitney e Kruskal-Wallis, com significância para $P<0,05$. Resultados - Não houve diferença entre a absorção duodenal de ferro dos grupos 1 e 2, assim como na curva de absorção. Conclusões - Conclui-se que, nas condições deste experimento, o consumo prolongado de etanol não alterou a absorção de ferro.
\end{abstract}

DESCRITORES - Absorção intestinal. Bebidas alcoólicas. Etanol. Ferro. Camundongos.

\section{INTRODUÇÃO}

O ferro é essencial ao metabolismo, atuando diretamente nas reações celulares ou como cofator para centenas de proteínas ${ }^{(2,6,19)}$. A quantidade total de ferro presente no corpo humano é de aproximadamente $4 \mathrm{~g}$, permanecendo constante durante toda a vida adulta, devido ao balanço entre a sua absorção e excreção( ${ }^{(6)}$.

Embora pouco conhecidos, existem mecanismos fisiológicos destinados a garantir a manutenção do conteúdo total de ferro dentro de estreita faixa de concentração sérica. O seu conteúdo total é determinado mais pela limitação a sua entrada no organismo, do que pela excreção aumentada, que constitui via habitual de equilíbrio dos eletrólitos ${ }^{(1,2,3)}$.

Além dos mecanismos reguladores da mucosa intestinal, o aporte de ferro do organismo é determinado por sua biodisponibilidade, que está relacionada à estrutura química, $\mathrm{pH}$ intraluminar presença de compostos facilitadores de sua absorção na $\operatorname{dieta}^{(6,14,16,17,23)}$.

Não há absorção de ferro no estômago, apesar de ser o ácido do estômago responsável pela emulsificação dos alimentos ingeridos, liberação do ferro e sua redução para a forma férrica, processos fundamentais para absorção desse elemento pela mucosa intestinal ${ }^{(6)}$. A maior parte da absorção de ferro ocorre no duodeno e no jejuno proximal. No entanto, se houver aceleração do transito sua absorção é reduzida ${ }^{(2,7)}$.

As células das criptas duodenais detectam a necessidade de ferro e preparam o enterócito maduro para a absorção desse metal. Estudos recentes evidenciam que a hepadicina, um peptídio sintetizado no fígado, é fundamental para mediar aos enterócitos, macrófagos e outras células do corpo a demanda de ferro ${ }^{(12)}$. Quando ocorre aumento da necessidade de ferro, a concentração da hepadicina diminui, aumentando a absorção do ferro. A concentração de transferrina atua como regulador da produção de hepadicina ${ }^{(8,21)}$.

A absorção do ferro inorgânico é influenciada por múltiplos fatores. Quando ele é ingerido isoladamente ou associado a proteínas animais e ácido ascórbico, sua absorção aumenta, enquanto a ingestão do ferro associado a cereais, celulose e hemicelulose, pectina, cálcio ou outros metais apresenta absorção reduzida ${ }^{(1,13,22)}$.

O papel da ingestão alcoólica na absorção intestinal de ferro ainda não está definido, apesar de ser observado aumento de aproximadamente $30 \%$ na quantidade de ferro presente no fígado de pacientes alcoolistas,

Departamento de Cirurgia da Faculdade de Medicina da Universidade Federal de Minas Gerais - UFMG; Santa Casa de Belo Horizonte, Belo Horizonte, MG.
${ }^{1}$ Santa Casa de Belo Horizonte; ${ }^{2}$ Departamento de Cirurgia da Faculdade de Medicina - UFMG; ${ }^{3}$ Médica.

Correspondência: Prof. Andy Petroianu - Av. Afonso Pena, n 1626, Apto 1901 - CEP 30130-005 - Belo Horizonte, MG. E-mail: petroian@medicina.ufmg.br 
independentemente da gravidade da lesão hepática ${ }^{(4,15)}$. Segundo alguns autores, há aumento da absorção de ferro quando ingerido com bebida alcoólica ${ }^{(4,15,16)}$. Por outro lado, deficiência nutricional associada ao alcoolismo reduz o nível de ferro sérico e resulta em anemia ${ }^{(12,17)}$. Este estudo teve como objetivo verificar a absorção de ferro no duodeno e a influência do consumo prolongado do etanol em sua absorção.

\section{MÉTODO}

Este estudo foi realizado de acordo com as recomendações das Normas Internacionais de Proteção aos Animais e foi submetido a aprovação do Comitê de Ética em Experimentação Animal (CETEA) da Universidade Federal de Minas Gerais.

Foram estudados 10 camundongos machos da raça Swiss, com peso inicial entre 25 e $30 \mathrm{~g}$, obtidos no biotério da Fundação Ezequiel Dias, Belo Horizonte, MG. Os camundongos foram distribuídos aleatoriamente em dois grupos:

- $\quad$ grupo $1(\mathrm{n}=5)$ - controle

- $\quad$ grupo $2(\mathrm{n}=5)$ - submetidos a ingestão prolongada de álcool etílico.

Para a indução do alcoolismo, foi ofertada como única fonte de água uma solução aquosa, que continha inicialmente $50 \mathrm{~mL} / \mathrm{L}$ de etanol, com aumentos semanais progressivos da concentração alcoólica de $50 \mathrm{~mL} / \mathrm{L}$ até a concentração final de $200 \mathrm{~mL} / \mathrm{L}$, que foi mantida por 13 semanas. Esta concentração de etanol administrada aos animais baseou-se em Gomes-Ayala et al. ${ }^{(10)}$. Previamente, em estudo piloto, cinco animais foram mortos na $12^{\mathrm{a}}$ semana, para estudo da alcoolemia, dosagem de gama glutamiltransferase e estudo histológico do fígado para verificar se os animais tinham alcoolemia crônica. Os animais receberam ração padrão para camundongos.

Decorrido o período de acompanhamento, os animais foram privados de alimento por 12 horas e submetidos a anestesia geral com injeção de pentabarbitúrico (tiopental ${ }^{\circledR}$, Cristália, Itapira, SP) na dose de 3,5 mg/animal $(90 \mathrm{mg} / \mathrm{kg})$ e citrato de fentanila (fentanil ${ }^{\circledR}$, Janssen-Cilag, São Paulo, SP) $2,5 \mu \mathrm{g} / \mathrm{animal}(60 \mu \mathrm{g} / \mathrm{kg})$ por via intraperitonial. Foi realizada uma incisão abdominal mediana e dissecou-se o duodeno com preservação do pedículo vasculonervoso. Isolou-se a parte proximal do estômago e todo o duodeno até o jejuno proximal. Por uma abertura gástrica pré-pilórica, introduziu-se uma cânula, que atravessava o piloro até a parte proximal do duodeno, para perfusão dos fluidos. Através do jejuno proximal foi introduzida outra cânula em direção ao duodeno distal, para a coleta dos fluidos. Ambas as cânulas foram amarradas com fio de seda $2-0^{(9,10)}$. As bordas da incisão abdominal foram aproximadas e cobertas por gazes embebidas em solução salina, para evitar a desidratação e o ressecamento do conteúdo intra-abdominal.

Todos os animais foram submetidos a perfusão intestinal com solução fisiológica $\left(0,0099 \mathrm{~g} / \mathrm{L}\right.$ de $\mathrm{CuSO}_{4} 5 \mathrm{H}_{2} \mathrm{O}, 0,0057$ $\mathrm{g} / \mathrm{L}$ de $\mathrm{ZnCO}_{3} 0,440 \mathrm{~g} / \mathrm{L}$ de $\mathrm{NaH}_{2} \mathrm{PO}_{4} \mathrm{H}_{2} \mathrm{O}, 0,335 \mathrm{~g} / \mathrm{L}^{2}$ de $\mathrm{Cl}_{2} \mathrm{Mg}$ $6 \mathrm{H}_{2} \mathrm{O}, 0,697 \mathrm{~g} / \mathrm{L}$ de $\mathrm{Ca} 2 \mathrm{H}_{2} \mathrm{O}, 0,600 \mathrm{~g} / \mathrm{L}$ de $\mathrm{NaHCO}_{3} 8,020$ $\mathrm{g} / \mathrm{L}$ de $\mathrm{ClNa}$ e $1,0 \mathrm{~g} / \mathrm{L}$ de glicose) à temperatura ambiente,
pH 6,4, a velocidade de $9 \mathrm{~mL} / \mathrm{h}$, durante 20 minutos, com objetivo de limpar a alça intestinal. Em seguida, foi iniciada a perfusão com solução fisiológica adicionada de $\mathrm{FeSO}_{4} 7 \mathrm{H}_{2} \mathrm{O}$ (Labsynth, São Paulo, SP) na concentração de $0,016 \mathrm{~g} / \mathrm{L}$ de ferro elemento associado a $0,145 \mathrm{mg} / \mathrm{dL}$ de ácido ascórbico (Labsynth, São Paulo, SP) à velocidade de infusão de 9 $\mathrm{mL} / \mathrm{h}$, por um período de 120 minuto, também de acordo com Gomes-Ayala et al..$^{(9,10)}$.

Todo o efluente foi colhido em períodos de 20 minutos e medido em proveta graduada. A concentração de ferro do efluente foi dosada por espectrofotometria de chama, por analisador automático (Merck, modelo mega). Em seguida, calculou-se a quantidade de ferro que foi absorvida, pela diferença de concentração desse elemento no líquido infundido e no efluente.

A comparação da absorção do ferro no duodeno utilizou o teste estatístico de Mann-Whitney para a comparação entre a quantidade de ferro absorvida nos diferentes tempos no mesmo animal, assim como a absorção total de ferro entre os diferentes grupos. O teste de Kruskal-Wallis comparou a quantidade de ferro absorvida entre os diferentes grupos por tempo. Os valores foram considerados significativos para $P<0,05^{(15,20)}$.

\section{RESULTADOS}

Todos os animais permaneceram sem anormalidades aparentes durante o período de acompanhamento.

Não houve diferença entre ferro no duodeno de camundongos controle, absorção de $7,71 \%$ do ferro total infundido, quando comparados com os submetidos ao consumo prolongado de álcool, com absorção de $8,06 \%$ do ferro total infundido $(P=0,9096)($ Tabela 1$)$

TABELA 1. Absorção total de ferro (\%) no duodeno em camundongos normais e após a ingestão crônica de álcool etílico

\begin{tabular}{lcc}
\hline Animais & $\begin{array}{c}\text { Grupo 1 } \\
\text { (controle) }\end{array}$ & $\begin{array}{c}\text { Grupo 2 } \\
\text { (alcoolismo crônico) }\end{array}$ \\
\hline 1 & 5,04 & 3,37 \\
2 & 6,38 & 5,02 \\
3 & 7,24 & 7,77 \\
4 & 7,86 & 10,10 \\
5 & 12,03 & 14,04 \\
Média \pm DP $^{*}$ & $7,71 \pm 1,17$ & $8,06 \pm 1,88$ \\
\hline
\end{tabular}

*P=0,9096

Houve intensa captação de ferro pelo duodeno de ambos os grupos nos primeiros 20 minutos, com média de $34,65 \%$ no grupo com ingestão prolongada de álcool e $20 \%$ nos controles. A concentração de ferro absorvido reduziu nos tempos seguintes, sendo a variação significante no grupo controle $(P=0,0122)$ e houve aumento da absorção, após 100 minutos, sem significância $(P=0,2963)$. No Grupo 2 , a captação de ferro aumentou aos 80 minutos $(P=0,6761)$, seguida de queda em sua absorção $(P=0,0367)$ nos 100 minutos, resultando em eliminação média de $5,75 \%$ do ferro infundido nesse período (Tabela 2). 
TABELA 2. Absorção percentual de ferro no duodeno de camundongos controles (grupo 1) e após ingestão prolongada de etanol (grupo 2)

\begin{tabular}{lcc}
\hline \multirow{2}{*}{$\begin{array}{l}\text { Tempos } \\
(\text { min) }\end{array}$} & \multicolumn{2}{c}{ Percentagem de ferro } \\
\cline { 2 - 3 } & $\begin{array}{c}\text { Grupo 1 } \\
\text { (controle) }\end{array}$ & $\begin{array}{c}\text { Grupo 2 } \\
\text { (alcoolismo crônico) }\end{array}$ \\
\hline 20 & 20,00 & 34,65 \\
40 & 6,14 & 6,64 \\
60 & 2,68 & 1,87 \\
80 & 4,82 & 7,87 \\
100 & 5,54 & 5,75 \\
120 & 7,45 & 3,13 \\
\hline
\end{tabular}

\section{DISCUSSÃO}

Neste experimento não houve mudança na absorção de ferro no duodeno de camundongos submetidos a ingestão prolongada de álcool etílico. Resultados semelhantes foram encontrados em ratos por Murray e Stein ${ }^{(18)}$ e em indivíduos alcoolistas por Chapman et al. ${ }^{(4)}$. No entanto, existem na literatura outros experimentos que apresentam dados discordantes, com aumento da absorção de ferro após consumo crônico de etanol ${ }^{(5,11,12,15)}$.

Os resultados conflitantes podem ser decorrentes dos diversos métodos utilizados nos experimentos, assim como, de estoques de ferro inadequados, hemólise e anemia sideroblástica, condições que se encontram frequentemente associadas ao alcoolismo ${ }^{(4,15)}$.

Chapman et al. ${ }^{(4)}$ não encontrou alteração na captação de ferro nos indivíduos alcoolistas que possuíam estoque de ferro orgânico normal; no entanto, houve aumento na absorção desse elemento nos pacientes com anemia, indicando que o consumo crônico de álcool etílico não afeta a absorção intestinal de ferro.

A absorção de ferro no organismo ocorre em três etapas: captação pela mucosa, retenção no enterócitos e transferência para o plasma ${ }^{(1,2,6)}$. Este experimento visou à primeira fase desse processo.

Grande quantidade de fatores externos interfere na absorção de ferro, dificultando a compreensão dos mecanismos reguladores da concentração desse metal no organismo ${ }^{(1,3}$, $5,7,8,11,13,14,17,21)$. No presente estudo, procurou-se reduzir a influência externa no mecanismo de absorção, através da perfusão de solução salina com ascorbato de ferro II em alça isolada.

Durante os primeiros 20 minutos, ambos os grupos apresentaram captação maior de ferro. Esse achado corrobora com a hipótese já descrita na literatura de que as células colunares da mucosa intestinal incorporam o ferro intrínseco do organismo, o que resulta na ocupação parcial dos receptores para esse elemento. Em presença de quantidade excessiva de ferro, os receptores podem saturar-se, dificultando a entrada de ferro proveniente do lume intestinal ${ }^{(1,2,6)}$.

\section{CONCLUSÃO}

No presente estudo, não foi observada alteração na absorção duodenal de ferro após ingestão prolongada de solução aquosa de álcool etílico. Nos primeiros 20 minutos, a captação de ferro pelo duodeno é maior.

Sabino KR, Petroianu A, Alberti LR, Machado AN. The effect of chronic ethanol consumption on duodenal absorption of iron in mice. Arq Gastroenterol. 2010;47(2):193-6.

ABSTRACT - Context - Alcoholists present an increase of iron hepatic concentration, although the responsible mechanisms for this deposition are still unknown. Despite the extensive literature related on the iron absorption in different pathological conditions, the effect of chronic ethanol consumption are still not conclusive and not completely understood. Objective - To verify the effect of chronic ethanol ingestion on duodenal absorption of iron. Methods - Ten male Swiss mice were divided into two groups: group $1(\mathrm{n}=5)$ - control, and group $2(\mathrm{n}=5)$ - water consumption with ethanol, as only water source. The animals were followed during 120 days. After this period, the duodenum was isolated and saline solution containing ascorbate of iron II in the 0,016 concentration of $\mathrm{mg}$ of iron element was infused. The effluent was collected in times 20, 40, 60, 80, 100 and 120 minutes. The results were analyzed by Mann-Whitney and Kruskal-Wallis tests. The significance was set for $P<0.05$. Results - No difference was found between iron absorption as well as iron absorption curves in groups 1 and 2. Conclusion - The chronic consumption of ethanol did not alter iron absorption

HEADINGS - Intestinal absorption. Alcoholic beverages. Ethanol. Iron. Mice.

\section{REFERENCES}

1. Andrews NC. Disorders of iron metabolism. N Engl J Med. 1999·341:1986-95.

2. Beard JL, Dawson H, Piñero JD. Iron metabolism. Nutr Rev. 1996;54:295-317.

3. Beutler E. How little we know about the absorption of iron. Am J Clin Nutr. 1997;66:419-20.

4. Chapman RW, Morgan MY, Boss AM, Sherlock S. Acute and chronic effects of alcohol on iron absorption. Dig Dis Sci. 1983;28:321-7.

5. Charlton RW, Jacobs P, Seftel H, Bothwell TH. Effect of alcohol on iron absorption. Br Med J. 1964;2:1427-29.

6. Conrad ME, Umbreit JN, Morre EG. Iron absorption and transport. Am J Clin Sci. 1999;318:213-9.

7. Conrad ME, Umbreit JN. Iron absorption and transport. Am J Hematol. 2000;64:287-98.
8. Ganz T, Nemeth E. Regulation of iron acquisition and iron distribution in mammals. Biochim Biophys Acta. 2006;7:690-9.

9. Gómez-Ayala AE, Lisbona F, López-Ayala I, Pallarés I, Barrionuevo M, Hartiti S, Rodríguez-Matas MC, Campos MS. The absorption of iron, calcium, phosphorus, magnesium, cooper and zinc in the jejunum-ileum of control and iron-deficient rats. Am J Clin Nutr. 1990;54:72-9.

10. Gómez-Ayala AE, Campos MS, López-Aliaga I, Pallarés I, Hartiti S, Barrionuevo M, Alférez MJM, Rodríguez-Matas MC, Lisbona F. Effect of source of iron on duodenal absorption iron, calcium, phosphorus, magnesium copper and zinc in rats with ferropoenic anaemia. Int J Vitam Nutr Res. 1997;67: 106-14.

11. Greenberg MS, Strohmeyer G, Hine GJ, Kenne WR, Curtis G, Chalmers TC. Body radioactivity measurements of patients with livers disease. Gastroenterology. 1964:46:651-61. 
12. Hallberg L, Hultén L, Elizabet G. Iron absorption from the whole diet in men. Am J Clin Nutr. 1997;66:247-356.

13. Hugerford DM, Linder MC. Interactions of $\mathrm{pH}$ and ascorbate in intestinal iron absorption. J Nutr. 1983;113:2615-22.

14. Hurrel RF. Bioavailability of iron. Eur J Clin Nutr. 1997;51(suppl 1):s4-s8.

15. Mazzanti R, Srai KS, Debnam ES, Boss AM, Gentilini P. The effect of chronic ethanol consumption on iron absorption in rats. Alcohol Alcohol. 1987;22:47-52.

16. Money SR, Petroianu A, Kimura K. The effect of short-term ethanol exposure on the canine jejunal handling of calcium and glucose. Surgery. 1990;107:167-71.

17. Müller-Fasbender M, Elsenhans B, Mckie AT, Schümann. Different behaviour of $63 \mathrm{Ni}$ e $59 \mathrm{Fe}$ during absorption in iron deficient and iron adequate jejunal rats segments ex vivo. Toxicology. 2003;185:141-53.

18. Murray J, Stein N. Effect of ethanol on absorption of iron in rats. Proc Soc Exp Biol Med. 1965;120:816-9.
19. Roy CN, Enns CA. Iron homeostasis. Blood. 2000;96:4020-7.

20. Sampaio IBM. Estatística aplicada a experimentação animal. Belo Horizonte: Fundação de Ensino a Pesquisa em Medicina Veterinária e Zootecnia; 1998. 221p.

21. Steele TM, Frazer DM, Anderson GJ. Systemic regulation of intestinal iron absorption Life. 2005;57:499-503.

22. Tinawi M, Martin KJ, Bastini B. Oral iron absorption test in patients on CADP comparison of ferrous sulfate and a polysaccharide ferric complex. Nephron. 1996;74:291-4

23. Trinidad TP, Valdez DH, Mallilin AC, Askali FC, Dara-ug AF, Capanzana MV The effect of different iron fortificants on iron absorption from iron-fortified rice. Food Nutr Bull. 2002;23:203-8.

Received 22/12/2008

Accepted 6/5/2009 